\title{
Correlation between angiopoietin-like proteins in inflammatory mediators in peripheral blood and severity of coronary arterial lesion in patients with acute myocardial infarction
}

\author{
YUEJUAN CAO ${ }^{1}$, RONGQING $\mathrm{LI}^{2}$, FENGPING ZHANG ${ }^{1}$, ZHAOZENG GUO $^{1}$, SHAOYONG TUO ${ }^{1}$ and YUMING LI $^{3}$ \\ Departments of ${ }^{1}$ Cardiology and ${ }^{2}$ Vascular Surgery, Tianjin Union Medical Center, Tianjin 300121; \\ ${ }^{3}$ Department of Radiology, Pingjin Hospital Heart Center and Tianjin, Key Laboratory of Cardiovascular \\ Remodeling and Target Organ Injury, Logistics University of PAPF, Tianjin 300162, P.R. China
}

Received October 15, 2018; Accepted February 21, 2019

DOI: $10.3892 /$ etm.2019.7386

\begin{abstract}
The effects of angiopoietin-like protein 2 (Angptl 2) and interleukin-6 (IL-6) in inflammatory mediators on the severity of coronary arterial lesion in patients with acute myocardial infarction were investigated. One hundred and twenty-six patients with acute myocardial infarction admitted to Tianjin Union Medical Center (the myocardial infarction group) and 133 healthy individuals (the control group) were selected for retrospective analysis from January 2013 to December 2015. The levels of Angptl 2 and IL-6 in serum of patients were detected by enzyme linked immunosorbent assay (ELISA), and the correlation analysis between the levels and the degree of coronary stenosis in patients with myocardial infarction was conducted. The expression level of Angptl 2 and IL-6 in the myocardial infarction group was significantly higher than that in the control group $\mathrm{P}<0.001$. In the myocardial infarction group, the expression levels of Angptl 2 and IL-6 were the highest in the patients with severe stenosis, followed by the moderate stenosis, and the lowest in the patients with mild stenosis $(\mathrm{P}<0.050)$. Pearson's correlation analysis showed that Angptl 2 and IL-6 were positively correlated with the diameter of coronary stenosis $(\mathrm{r}=0.696,0.750, \mathrm{P}<0.001)$. In conclusion, both Angptl 2 and IL-6 are highly expressed in the peripheral blood of patients with acute myocardial infarction and involved in the occurrence and development of the disease. Moreover, Angpt12 and IL-6 are positively correlated with the severity of coronary arterial lesion in patients with acute myocardial infarction, and they are expected to become a target for the diagnosis and treatment of coronary atherosclerosis (CA) in the future.
\end{abstract}

Correspondence to: Dr Yuming Li, Department of Radiology, Pingjin Hospital Heart Center and Tianjin, Key Laboratory of Cardiovascular Remodeling and Target Organ Injury, Logistics University of PAPF, 220 Chenglin Street, Tianjin 300162, P.R. China E-mail: drcyjuan@163.com; cardiolab@live.com

Key words: acute myocardial infarction, Angptl 2, IL-6, coronary arterial lesion

\section{Introduction}

Coronary atherosclerosis (CA), a cardiovascular disease that seriously endangers human health, is more common in middleaged and elderly individuals, and it easily causes diseases such as hypertension, coronary heart disease and myocardial infarction, which is a great threat to humans and very difficult to treat (1). The number of CA cases in the world is still on the rise. According to statistics, the world's new CA patients exceeded 80 million in $2016(2,3)$. Data show that in some countries with a large population (such as China and India), the cumulative number of CA patients has exceeded 300 million (4). At present, CA is already the most common cardiovascular disease in clinic, with about one in every five individuals (5). The course of CA is extremely slow, usually with no special clinical symptoms at the early stage, but as the disease progresses, it usually manifests multiple complications, such as hypertension, coronary heart disease, heart failure and myocardial infarction (6). CA patients generally need a long treatment cycle, and the data show that the complete cure rate of CA is less than $20 \%$ (7). As a result, the mortality of CA remains high and with the 5-year survival rate of only $30-40 \%$ (8). Because of the high incidence, high injury and refractoriness of CA, it is regarded as an important research focus in the clinic. However, the pathogenesis of CA is not completely clear at present, and many studies worldwide have proven that the occurrence and development of CA involves a large number of cellular and non-cellular biological processes (9-11).

Angiopoietin-like proteins (Angptls) are secreted glycoproteins that have been discovered in recent years and are closely related to angiogenesis and have high homology with angiopoietin (Ang) (12). Angiopoietin-like protein 2 (Angptl 2) is mainly expressed and secreted by visceral fat cells and has been proven not only to have the ability to regulate angiogenesis, but also a process of strong force for survival and repair of hematopoietic stem cells, and it has a correlation with diabetes and autoimmune diseases $(13,14)$. Shimomura et al (15) proposed that Angptl 2 could damage the vascular endothelium of patients by regulating inflammatory factors. However, there are few studies on Angptl 2 and CA worldwide, and their influence is still unclear. Therefore, 
patients with acute myocardial infarction admitted to Tianjin Union Medical Center (Tianjin, China) from January 2013 to December 2015 were selected as research subjects to analyze the expression of Angptl 2 and its effect on coronary arterial lesion and interleukin-6 (IL-6) in patients with myocardial infarction, to explore the role of Angptl 2 in CA and provide reference for its future clinical diagnosis and treatment.

\section{Patients and methods}

Patient data. One hundred and twenty-six patients with acute myocardial infarction in Tianjin Union Medical Center (the myocardial infarction group) from January 2013 to December 2015 and 133 healthy individuals (the control group) were selected for retrospective analysis. In the myocardial infarction group, there were 72 males and 54 females, aged 38-73 years and with an average age of $56.36 \pm 13.17$ years, and the pathological changes were classified according to the results of coronary arteriography. In the control group, there were 84 males and 49 females, aged 35-70 years and with an average age of $54.62 \pm 11.87$ years. Inclusion criteria for the myocardial infarction group were: Patients with acute ST segment elevation in electrocardiogram and diagnosed as acute myocardial infarction; patients with complete cases; and patients receiving no related treatment in other hospitals. Exclusion criteria were: Patients unwilling to undergo coronary arteriography; patients allergic to coronary arteriography agents; patients during pregnancy and lactation; patients with other serious cardiovascular diseases or tumors; patients with severe liver and renal dysfunction; and patients with communication or cognitive impairment. All subjects and their families signed an informed consent, and cooperated with the medical staff to complete the diagnosis and treatment.

The study was approved by the Ethics Committee of Tianjin Union Medical Center.

Detection methods of Angptl 2 and IL-6 levels. Peripheral venous blood $(4 \mathrm{ml})$ was taken from the patients of the two groups in the fasting state, and the serum was separated by centrifugation at $8,200 \times \mathrm{g}$ for $15 \mathrm{~min}$ at $4^{\circ} \mathrm{C}$, then stored in a cryogenic refrigerator at $-80^{\circ} \mathrm{C}$ (Meling Biology and Medical, Hefei, China) for testing. The expression levels of Angptl 2 and IL-6 were detected by enzyme linked immunosorbent assay (ELISA) in strict accordance with the instructions of Angptl 2 ELISA detection kit (Shenzhen Kerunda Biotech Co., Ltd., Shenzhen, China, cat. no. 27409) and human IL-6 ELISA detection kit (Shanghai Qiaoyu Biotechnology Co., Ltd., Shanghai, China, cat. no. QY-SE0049).

Determination of coronary arteriongraphy and severity of coronary arterial lesion. The cardiac catheter was percutaneously inserted into the femoral artery of the lower extremity, retrograded along the aorta descendens to the root of the aorta ascendens, and then inserted into the ostium of the left or right coronary artery. The contrast agent was injected to develop the coronary artery. The degree of coronary stenosis was divided according to the results: i) Mild stenosis: $>50 \%-\leq 70 \%$ diameter of coronary stenosis; ii) Moderate stenosis: $>70 \%-\leq 89 \%$ diameter of coronary stenosis; iii) Severe stenosis: diameter of coronary stenosis $\geq 90 \%$.

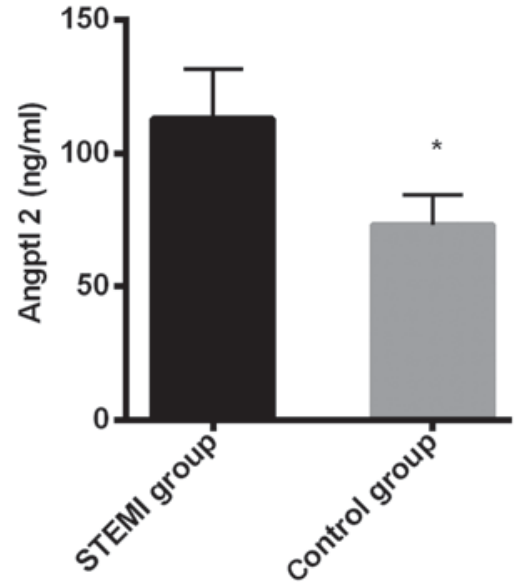

Figure 1. Comparison of the expression level of Angptl 2 between the two groups. The expression level of Angptl 2 in the myocardial infarction group was significantly higher than that in the control group. ${ }^{*} \mathrm{P}<0.050$, compared with the expression level of Angptl 2 in the myocardial infarction group.

Statistical analysis. PSS 17.4 software system (Shanghai Yuchuang Network Technology Co., Ltd., Shanghai, China) was used for statistical analysis. The basic enumeration data of patients are expressed by percentage [n (\%)] and detected by $\chi^{2}$ test. The expression levels of Angptl 2 and IL- 6 were expressed as mean \pm standard deviation, the difference between the two groups was analyzed by t-test. ANOVA with LSD post hoc test was uesd for the comparison of multiple groups. The correlation between the degree of coronary stenosis and Angptl 2, IL-6 in the myocardial infarction group was analyzed by Pearson's correlation analysis. $\mathrm{P}<0.05$ was considered to indicate a statistically significant difference.

\section{Results}

Comparison of clinical data between the two groups. In order to make the results accurate and reliable, there was no significant difference in sex, age, symptoms such as headache, dizziness, facial paralysis or hearing loss in the two groups when compared, and the results showed no significant difference $(\mathrm{P}>0.05)$, indicating that the patients in the two groups were comparable. Details of the patient information are shown in Table I.

Expression levels of Angptl 2 and IL-6 in serum of the two groups. The expression level of Angptl 2 in the myocardial infarction group $(112.83 \pm 18.74 \mathrm{ng} / \mathrm{ml})$ was significantly higher than that in the control group $(73.18 \pm 11.29 \mathrm{ng} / \mathrm{ml})$, and the difference was statistically significant $(\mathrm{t}=20.750, \mathrm{P}<0.001)$; The expression level of IL- 6 in the myocardial infarction group $(198.36 \pm 19.37 \mathrm{U} / \mathrm{ml})$ was significantly higher than that in the control group $(97.47 \pm 8.37 \mathrm{U} / \mathrm{ml})$, and the difference was statistically significant $(\mathrm{P}=54.910, \mathrm{P}<0.001)$ (Figs. 1 and 2$)$.

Expression levels of Angptl 2 and IL-6 in serum of patients with different degrees of coronary stenosis in the myocardial infarction group. Angptl 2 in patients with mild stenosis was $91.21 \pm 10.36 \mathrm{ng} / \mathrm{ml}$, in patients with moderate stenosis $110.16 \pm 12.68 \mathrm{ng} / \mathrm{ml}$, and in patients with severe stenosis it was $123.83 \pm 23.47 \mathrm{ng} / \mathrm{ml}$. There was significant difference in the 
Table I. Basic information of patients $[\mathrm{n}(\%)]$.

\begin{tabular}{|c|c|c|c|c|}
\hline Factors & $\begin{array}{l}\text { Myocardial infarction } \\
\text { group }(\mathrm{n}=126)\end{array}$ & Control group $(n=133)$ & $\chi^{2}$ or $t$ value & P-value \\
\hline Sex & & & 0.977 & 0.323 \\
\hline Male & $72(57.14)$ & $84(63.16)$ & & \\
\hline Female & $54(42.86)$ & $49(36.84)$ & & \\
\hline Age (years) & & & 0.350 & 0.554 \\
\hline$\leq 45$ & $49(38.89)$ & $47(35.34)$ & & \\
\hline$>45$ & $77(61.11)$ & $86(64.66)$ & & \\
\hline Systolic pressure (mmHg) & $145.16 \pm 10.25$ & $142.98 \pm 9.86$ & 1.745 & 0.082 \\
\hline Diastolic pressure (mmHg) & $78.21 \pm 8.33$ & $76.84 \pm 7.95$ & 1.354 & 0.177 \\
\hline $\mathrm{BMI}\left(\mathrm{kg} / \mathrm{m}^{2}\right)$ & $23.8 \pm 3.4$ & $23.1 \pm 2.8$ & 1.813 & 0.071 \\
\hline Smoking & & & 3.081 & 0.079 \\
\hline Yes & $88(69.84)$ & $79(59.40)$ & & \\
\hline No & $38(30.16)$ & $54(40.60)$ & & \\
\hline Drinking & & & 0.260 & 1.268 \\
\hline Yes & $76(60.32)$ & $71(53.38)$ & & \\
\hline No & $50(39.68)$ & $62(46.62)$ & & \\
\hline Severity of coronary stenosis & & & - & - \\
\hline Mild stenosis & $65(51.59)$ & - & & \\
\hline Moderate stenosis & $47(37.30)$ & - & & \\
\hline Severe stenosis & $14(11.11)$ & - & & \\
\hline
\end{tabular}

Table II. The expression levels of Angptl 2 and IL-6 in serum of patients with different degrees of coronary stenosis in the myocardial infarction group.

\begin{tabular}{lccrr}
\hline Mediators & $\begin{array}{c}\text { Mild stenosis } \\
(\mathrm{n}=65)\end{array}$ & $\begin{array}{c}\text { Moderate stenosis } \\
(\mathrm{n}=47)\end{array}$ & $\begin{array}{c}\text { Severe stenosis } \\
(\mathrm{n}=14)\end{array}$ & F value \\
\hline Angptl 2 (ng/ml) & $91.21 \pm 10.36$ & $110.16 \pm 12.68^{\mathrm{a}}$ & $123.83 \pm 23.47^{\mathrm{b}}$ & 49.850 \\
IL-6 (U/ml) & $155.83 \pm 14.48$ & $196.47 \pm 18.92^{\mathrm{a}}$ & $214.15 \pm 17.61^{\mathrm{b}}$ & 129.100 \\
\hline
\end{tabular}

${ }^{\mathrm{a}} \mathrm{P}<0.05$, compared with patients with mild stenosis, there was statistical significance; ${ }^{\mathrm{b}} \mathrm{P}<0.05$, compared with patients with moderate stenosis, there was statistical significance.

expression of Angptl 2 in the serum of patients with different degrees of coronary stenosis $(\mathrm{P}<0.001)$. The expression levels of Angptl 2 were the highest in the patients with severe stenosis, followed by moderate stenosis, and the lowest in the patients with mild stenosis $(\mathrm{P}<0.050)$. IL-6 in patients with mild stenosis was $155.83 \pm 14.48 \mathrm{ng} / \mathrm{ml}$, in patients with moderate stenosis $196.47 \pm 18.92 \mathrm{ng} / \mathrm{ml}$, and in patients with severe stenosis it was $214.15 \pm 17.61 \mathrm{ng} / \mathrm{ml}$. There was significant difference in the expression of IL- 6 in the serum of patients with different degrees of coronary stenosis $(\mathrm{P}<0.001)$. The expression levels of IL-6 were the highest in the patients with severe stenosis, followed by those with moderate stenosis, and the lowest in the patients with mild stenosis $(\mathrm{P}<0.050)$ (Table II).

Correlation analysis of expression levels of Angptl 2, IL-6 and stenosis diameter. Pearson's correlation analysis showed that Angptl 2 was positively correlated with the diameter of coronary stenosis $(\mathrm{r}=0.696, \mathrm{P}<0.001)$; IL- 6 was positively correlated with the diameter of coronary stenosis $(r=0.750$, $\mathrm{P}<0.001$ ) (Figs. 3 and 4).

\section{Discussion}

Cardiovascular disease was reported as the highest mortality in clinic, among which the most common disease is coronary atherosclerosis (CA) (16). Acute myocardial infarction is a very common complication in CA and its pathological mechanism is closely related to the sustained inflammatory response in vascular tissue. Intradermal cells cause vascular obstruction because of the blocking effect of inflammatory mediators, which leads to insufficient blood supply to the heart and the occurrence of myocardial infarction $(17,18)$. Therefore, finding an effective way to prevent atherosclerosis is a major research focus in clinical practice. With the deepening of research, 


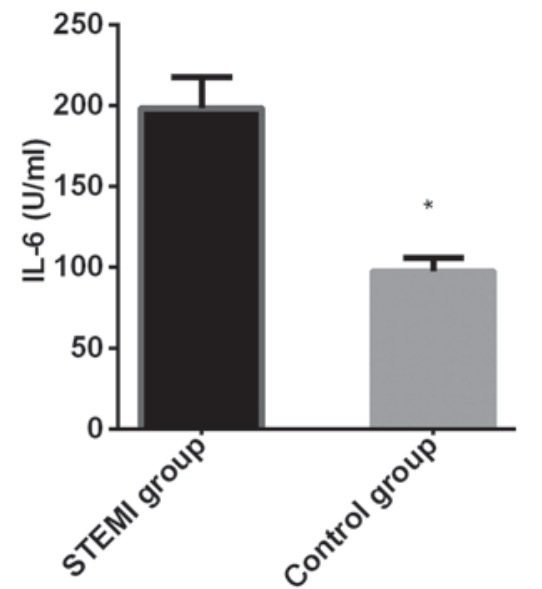

Figure 2. Comparison of the expression level of IL- 6 between the two groups. The expression level of IL-6 in myocardial infarction group was significantly higher than that in the control group. ${ }^{*} \mathrm{P}<0.050$, compared with the expression level of IL-6 in the myocardial infarction group.

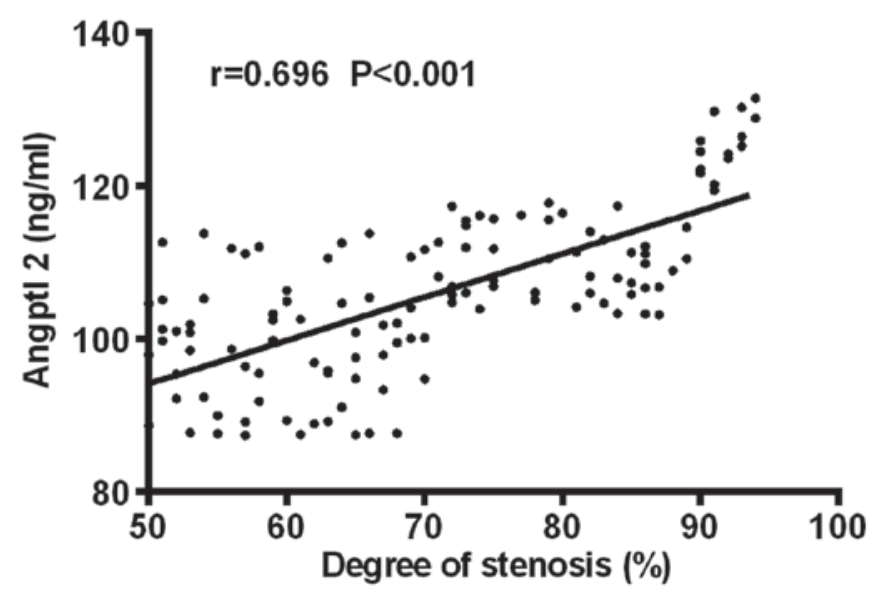

Figure 3. Correlation analysis of expression level of Angptl 2 and severity of coronary arterial lesion. Pearson's correlation analysis shows that Angptl 2 was positively correlated with the diameter of coronary stenosis $(r=0.696$, $\mathrm{P}<0.001)$.

Angptl 2 has been proven to play an important role in the damage of vascular endothelial cells and the promotion of macrophage infiltration in atheromatous plaques $(19,20)$, and it has become a hotspot in research of cardiovascular disease. Therefore, the expression levels of Angptl 2 and IL-6 in peripheral blood of patients with acute myocardial infarction were studied to analyze the effect of Angptl 2 on the severity of coronary arterial lesion.

The results of this evaluation showed that Angptl 2 and IL-6 were highly expressed in patients with acute myocardial infarction, suggesting that Angptl 2 and IL-6 are involved in the occurrence and development of myocardial infarction. In the pathogenesis of acute heart infarction, adipose tissue can secrete a large number of pro-inflammatory cytokines and antiinflammatory factors (21), which can be confirmed by the high expression of IL-6 in this experimental result. Because of the imbalance between pro-inflammatory and anti-inflammatory factors caused by the dysfunction of adipose tissue, a chronic inflammatory state occurs, which constantly destroys the integrity of the vascular endothelium in the patient's body,

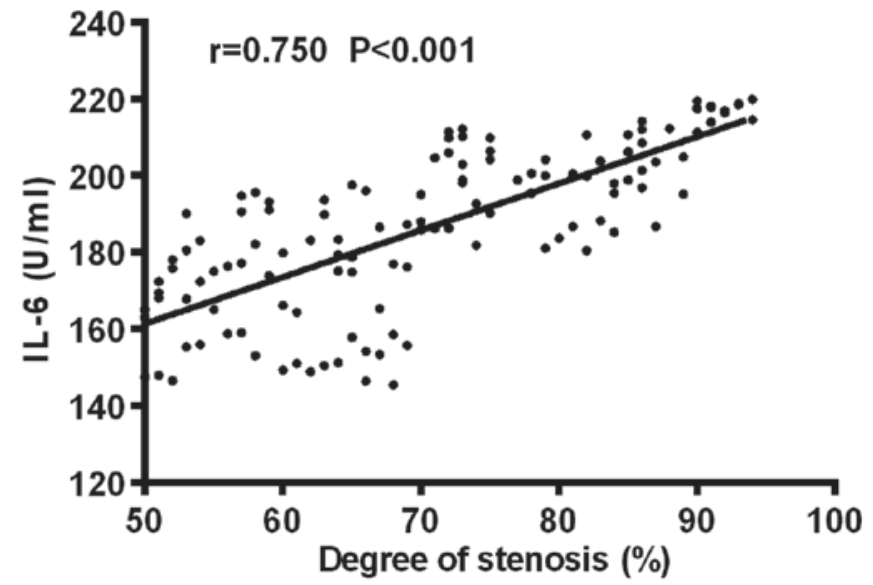

Figure 4. Correlation analysis of expression level of IL-6 and severity of coronary arterial lesion. Pearson's correlation analysis shows that IL-6 was positively correlated with the diameter of coronary stenosis $(r=0.750$, $\mathrm{P}<0.001)$.

thereby promoting the progression of arterial lesions (22). Taketani et al (23) studied the adipose tissue of transplanted Angptl 2 transgenic mice and found that Angpt 2 could promote inflammation and intimal thickening of the neovascular wall. Therefore, it is speculated that the mechanism of Angptl 2 in patients with myocardial infarction may cause vascular endothelium dysfunction, induce the migration of endothelial cells in the coronary artery, stimulate the expression of endothelial proinflammatory cytokines and adhesion molecules, and accelerate as well as promote the occurrence of myocardial infarction.

In this study, it was shown that Angptl 2 and IL-6 were positively correlated with the severity of coronary arterial lesion in patients with acute myocardial infarction, indicating that Angptl 2 and IL-6 are closely related to coronary arterial lesion and expected to be a target for diagnosis and treatment of CA. The pathological mechanism of CA involves the loss of function of endothelial cells and the proliferation, migration, degradation of leukocytes, smooth muscle cells as well as the activation of platelets (24), and Angptl 2 is closely related to the changes of these cells. The study of Biscetti et al (25) showed that the use of Angptl 2 could significantly increase the size and cholesterol levels of atherosclerotic plaques in rats. Therefore, it is speculated that Angptl 2 can increase the secretion of inflammatory factors in the body of patients by inducing the pro-inflammatory response, thereby causing a significant increase in plasma cholesterol and low-density lipoprotein cholesterol, aggravating the progression of coronary atherosclerotic lesions. However, other mechanisms that induce cholesterol elevation have not yet been elucidated and need to be further studied.

The expression of Angptl 2 and IL-6 in peripheral serum of patients with acute myocardial infarction were studied in this research to analyze the correlation between Angptl 2 and the severity of coronary arterial lesion. However, due to the limited experimental conditions, there are still shortcomings. The number of subjects in the study was small and the sample size of other types of CA patients were not available for statistical analysis. The study population lacks different ethnic and age groups that may have different outcomes. The mechanism of Angptl 2 needs further research. 
In conclusion, both Angptl 2 and IL-6 are highly expressed in the peripheral blood of patients with acute myocardial infarction and involved in the occurrence and development of the disease. Moreover, Angptl 2 and IL- 6 are positively correlated with the severity of coronary arterial lesion in patients with acute myocardial infarction and are expected to become a target for the diagnosis and treatment of CA in the future.

\section{Acknowledgements}

Not applicable.

\section{Funding}

This study was supported by TJC1410 (Tianjin Key Laboratory of Cardiovascular Remodeling and Target Organ Injury open fund; Project name: Association study of peripheral blood neutrophil count and risk of acute thrombotic events in patients with acute coronary syndrome).

\section{Availability of data and materials}

The datasets used and/or analyzed during the present study are available from the corresponding author on reasonable request.

\section{Authors' contributions}

YC wrote the manuscript. YC and RL helped with ELISA. YL and FZ contributed to the determination of coronary arteriography and severity of coronary arterial lesion. ZG and ST were responsible for collection of the general data of the patients. The final version was read and adopted by all the authors.

\section{Ethics approval and consent to participate}

The study was approved by the Ethics Committee of Tianjin Union Medical Center (Tianjin, China). Signed written informed consents were obtained from the patients or their guardians.

\section{Patient consent for publication}

Not applicable.

\section{Competing interests}

The authors declare that they have no competing interests.

\section{References}

1. Stubbs JR, House JA, Ocque AJ, Zhang S, Johnson C, Kimber C, Schmidt K, Gupta A, Wetmore JB, Nolin TD, et al: Serum trimethylamine-N-oxide is elevated in CKD and correlates with coronary atherosclerosis burden. J Am Soc Nephrol 27: 305-313, 2016.

2. Kaplan H, Thompson RC, Trumble BC, Wann LS, Allam AH, Beheim B, Frohlich B, Sutherland ML, Sutherland JD, Stieglitz J, et al: Coronary atherosclerosis in indigenous South American Tsimane: A cross-sectional cohort study. Lancet 389: 1730-1739, 2017.
3. Ughi GJ, Wang H, Gerbaud E, Gardecki JA, Fard AM, Hamidi E, Vacas-Jacques P, Rosenberg M, Jaffer FA and Tearney GJ: Clinical characterization of coronary atherosclerosis with dualmodality OCT and near-infrared autofluorescence imaging. JACC Cardiovasc Imaging 9: 1304-1314, 2016.

4. Akboga MK, Canpolat U, Yayla C, Ozcan F, Ozeke O, Topaloglu S and Aras D: Association of platelet to lymphocyte ratio with inflammation and severity of coronary atherosclerosis in patients with stable coronary artery disease. Angiology 67: 89-95, 2016.

5. Nicholls SJ, Puri R, Wolski K, Ballantyne CM, Barter PJ, Brewer HB, Kastelein JJ, Hu B, Uno K, Kataoka Y, et al: Effect of the BET protein inhibitor, RVX-208, on progression of coronary atherosclerosis: Results of the phase $2 \mathrm{~b}$, randomized, doubleblind, multicenter, ASSURE trial. Am J Cardiovasc Drugs 16: 55-65, 2016.

6. Barbato E, Toth GG, Johnson NP, Pijls NH, Fearon WF, Tonino PA, Curzen N, Piroth Z, Rioufol G, Jüni P, et al: A prospective natural history study of coronary atherosclerosis using fractional flow reserve. J Am Coll Cardiol 68: 2247-2255, 2016.

7. Otsuka F, Yasuda S, Noguchi T and Ishibashi-Ueda H: Pathology of coronary atherosclerosis and thrombosis. Cardiovasc Diagn Ther 6: 396-408, 2016.

8. Furuhashi M, Fuseya T, Murata M, Hoshina K, Ishimura S, Mita T, Watanabe Y, Omori A, Matsumoto M, Sugaya T, et al: Local production of fatty acid-binding protein 4 in epicardial/ perivascular fat and macrophages is linked to coronary atherosclerosis. Arterioscler Thromb Vasc Biol 36: 825-834, 2016.

9. Koskinas KC, Windecker S and Räber L: Regression of coronary atherosclerosis: Current evidence and future perspectives. Trends Cardiovasc Med 26: 150-161, 2016.

10. Thondapu V, Bourantas CV, Foin N, Jang IK, Serruys PW and Barlis P: Biomechanical stress in coronary atherosclerosis: Emerging insights from computational modelling. Eur Heart J 38: 81-92, 2017.

11. Afrasyab A, Qu P, Zhao Y, Peng K, Wang H, Lou D, Niu N and Yuan D: Correlation of NLRP3 with severity and prognosis of coronary atherosclerosis in acute coronary syndrome patients. Heart Vessels 31: 1218-1229, 2016.

12. Dijk W and Kersten S: Regulation of lipid metabolism by angiopoietin-like proteins. Curr Opin Lipidol 27: 249-256, 2016.

13. Hata J, Mukai N, Nagata M, Ohara T, Yoshida D, Kishimoto H, Shibata M, Hirakawa Y, Endo M, Ago T, et al: Serum Angiopoietin-Like protein 2 is a novel risk factor for cardiovascular disease in the community: The Hisayama study. Arterioscler Thromb Vasc Biol 36: 1686-1691, 2016.

14. Morinaga J, Kadomatsu T, Miyata K, Endo M, Terada K, Tian Z, Sugizaki T, Tanigawa H, Zhao J, Zhu S, et al: Angiopoietin-like protein 2 increases renal fibrosis by accelerating transforming growth factor- $\beta$ signaling in chronic kidney disease. Kidney Int 89: 327-341, 2016.

15. Shimomura M, Oyama J, Takeuchi M, Shibata Y, Yamamoto Y, Kawasaki T, Komoda H, Kodama K, Sakuma M, Toyoda S, et al: Acute effects of statin on reduction of angiopoietin-like 2 and glyceraldehyde-derived advanced glycation end-products levels in patients with acute myocardial infarction: A message from SAMIT (Statin for Acute Myocardial Infarction Trial). Heart Vessels 31: 1583-1589, 2016.

16. Liberale L, Bonaventura A, Vecchiè A, Matteo C, Dallegri F, Montecucco F and Carbone F: The role of adipocytokines in coronary atherosclerosis. Curr Atheroscler Rep 19: 10, 2017.

17. Cheng JM, Oemrawsingh RM, Garcia-Garcia HM, Boersma E, van Geuns RJ, Serruys PW, Kardys I and Akkerhuis KM: PCSK9 in relation to coronary plaque inflammation: Results of the ATHEROREMO-IVUS study. Atherosclerosis 248: 117-122, 2016.

18. Dursunoglu N, Dursunoglu D, Yıldız AI, Uludag B, Alaçam ZN and Sarıçopur A: Severity of coronary atherosclerosis in patients with COPD. Clin Respir J 11: 751-756, 2017.

19. Amadatsu T, Morinaga J, Kawano T, Terada K, Kadomatsu T, Miyata K, Endo M, Kasamo D, Kuratsu JI and Oike Y: Macrophage-derived angiopoietin-like protein 2 exacerbates brain damage by accelerating acute inflammation after ischemiareperfusion. PLoS One 11: e0166285, 2016.

20. Hirasawa M, Takubo K, Osada H, Miyake S, Toda E, Endo M, Umezawa K, Tsubota K, Oike Y and Ozawa Y: Angiopoietin-like protein 2 is a multistep regulator of inflammatory neovascularization in a murine model of age-related macular degeneration. J Biol Chem 291: 7373-7385, 2016. 
21. Reed GW, Rossi JE and Cannon CP: Acute myocardial infarction. Lancet 389: 197-210, 2017.

22. Li C, Li C, Yue J, Huang X, Chen M, Gao J and Wu B: miR-21 and miR-101 regulate PLAP-1 expression in periodontal ligament cells. Mol Med Rep 5: 1340-1346, 2012.

23. Taketani Y, Usui T, Toyono T, Shima N, Yokoo S, Kimakura M, Yamagami S, Ohno S, Onodera R, Tahara K, et al: Topical use of angiopoietin-like protein 2 RNAi-loaded lipid nanoparticles suppresses corneal neovascularization. Mol Ther Nucleic Acids 5: e292, 2016.

24. Bobryshev YV, Ivanova EA, Chistiakov DA, Nikiforov NG and Orekhov AN: Macrophages and their role in atherosclerosis: pathophysiology and transcriptome analysis. BioMed Res Int 2016: 9582430, 2016.
25. Biscetti F, Straface G, Porreca CF, Bertoletti G, Vincenzoni C, Snider F, Stigliano E, Arena V, Angelini F, Pecorini G, et al: Increased FGF23 serum level is associated with unstable carotid plaque in type 2 diabetic subjects with internal carotid stenosis. Cardiovasc Diabetol 14: 139, 2015.

(7) (9) This work is licensed under a Creative Commons cy No No Attribution-NonCommercial-NoDerivatives 4.0 International (CC BY-NC-ND 4.0) License. 